\title{
A New Protocol For Teaching English Language Learners In Middle And Secondary Schools
}

\author{
John Luster, Ed. D., National University, San Diego, USA
}

\begin{abstract}
In the United States, the population of minority students in 2005 increased to 42 percent of public school enrollment (Echevarria \& Short, 2010). English learners (ELs) are the fastest growing population of students enrolled in public school across the United States. California alone has 1.5 million ELs attending public schools (Echevarria, 2008). During the 2007-2008 academic year, only 11 states met their accountability goals for ELs under the No Child Left Behind Act (August, and Shanahan, 2006, Zehr, 2011). If an EL speaks English with difficulty, 82 percent will not graduate from high school. A recent Texas study reported that 80 percent of ELs did not graduate from high school (Echevarria, Vogt, and Short, 2008).
\end{abstract}

The gap in academic achievement between Caucasian students and those from culturally and linguistically diverse groups has widened primarily because many middle and secondary classroom teachers are under prepared to make content comprehensible for ELs or to teach content-area literacy to a forgotten population of middle and secondary ELs (Echevarria and Short, 2010). The result is that ELs enrolled in middle and high schools have become long term ELs, who's specific learning needs for success in school are largely, ignored thus creating a large EL underachieving group (Olsen, 2010). Many middle and secondary schools engage in the common practice of segregating students in what some educators have called the "EL ghetto." The ELs middle and secondary school curriculum typically consists of a sequence of courses that keep them together over multiple years in classes that do not enable them to complete prerequisites for higher tracks of college (Darling-Hammond, 2010). The overarching question addressed in this presentation is; what do teachers need to know and be able to do to provide ELs with systematic language development, academic literacy skills, successful experiences in mainstream classes, meet content standards, and pass standardized assessments in their second language?

Keywords: English Learners; California English Language Development Test; English Language Development Classes; English Language Proficiency; Specifically Designed Academic Instruction in English; Sheltered instruction; Sheltered Instruction Observational Protocol

\section{INTRODUCTION}

$\mathrm{n}$ the United States, the fastest growing school populations are the ELs accounting for 42 percent of the total number of students enrolled in public schools in the United States. Nationally, students from linguistically and diverse groups continue to fall behind Caucasian students in academic achievement in middle and secondary schools, particularly in reading and mathematics (Echevarria, 2008; Echevarria, Vogt and Short, 2008). Studies of ELs have found that many teachers are underprepared to design and adapt lessons and assessments to make academic content comprehensible to ELs. Additionally, few teachers are prepared by education or training to teach initial literacy or content-area literacy to secondary ELs in reading, mathematics or science. The result is that schools have continued to create a permanent underclass of students who speak a primary language other than English (Echevarria, 2008). By classification, ELs are not English proficient. There are relatively few 
teachers, in the United States, with the know-how or inclination to spend four to seven years teaching ELs to reach average academic performance levels.

\section{The Status of Teaching English Learners In The United States}

Today, many urban school districts are struggling to staff highly qualified teachers under No Child Left Behind (NCLB) guidelines. In California, districts continue to lay off teachers in unprecedented numbers in an attempt to balance already tight state and district budgets.

Thirty-two states reported that during the 2004-2006 academic years, mathematics standardized test score gaps between limited English proficient (LEP) and English speaking students increased to 21 percent. The percentage of LEP students failing to score at or above the proficient level for mathematics averaged 74 percent in 2004-2005, and 63 percent in 2005-2006 (Pinkos, 2008).

State and national political rhetoric has shifted from general discussions of statements of what constitutes highly qualified and effective teaching to what teachers should know and be able to do. This discussion has escalated during the past few years led by an intensive development of educational policy in American history intended to address issues of teacher quality (White, M. E., Makkonen, R., and Stewart, K. B. (2009).

Additionally, national panel reports on the status of teacher credential programs recommend performance standards for teacher credential programs including recommendations for teaching ELs. A landmark study by Ferguson in 1991, supplied data that supported the notion that teacher's experience-as measured by scores on a licensing examination, master's degrees, and experience-accounted for about 40 percent of the measured variance in student reading and mathematics in grades 1-11. The Ferguson study asserted that after controlling for economic status, the large disparities in achievement between black and white students were almost entirely accounted for by differences in the qualifications of their teachers (Ferguson, 1991). The notion of raising teacher performance standards to positively effect student achievement continues to be fueled by recommendations of the National Board for Professional Teaching Standards (NBPTS), the Interstate New Teacher Assessment and Support Consortium (INTASC), and the performance-based standards of the National Council for Accreditation of Teacher Education (NCATE, 2009; Hitz, 2008). This paper discusses the need for a new research based protocol for teaching ELs in middle and secondary schools. .

\section{BODY}

\section{Teacher Quality and English Learners}

Historically, a 1996 a report from the National Commission on Teaching and America's Future contained the following challenge; "By the year 2006, America will provide every student with what should be his or her educational birthright: access to competent, caring and qualified teaching" (Darling-Hammond, 1997 p. 1). The report further discussed the relationship between student achievement and teacher skills by linking what teachers know and are able to do academically and pedagogically is crucial to what students learn (Darling-Hammond, 1997; Darling-Hammond \& Bell 1997; Darling-Hammond, 2008, and Honavar, 2008). These and other reports continued to support the contention that a highly qualified teacher contributes to raising student achievement. Several national projects including the five core propositions of the National Board for Professional Teaching Standards, Teaching Performance Expectations of individual State Departments of Education and the Common Core State Standards Initiative, contend that rigorous standards are necessary for the success of high school students (National Governors Association, Chief State School Officers and Achieve, 2008, and CTC, 2010). It follows that teachers of middle and secondary students need to be held to the same rigorous standards. 


\section{Implications of No Child Left Behind Legislation ${ }^{1}$}

Through authorization of the Higher Education Act, Congress imposed reporting regulations on all schools and colleges of education through Title II in an attempt to ensure the quality of teacher preparation programs. Using data from the Title II requirements, the U.S. Department of Education issued a report titled, "Meeting the Highly Qualified Teachers Challenge: The Secretary's Annual Report on Teacher Quality." The data collected from this report suggested that schools of education, and district teacher professional development programs were failing to produce highly qualified effective teachers that the NCLB Act demands. The report continued to question the value students receive from attending schools of education and recommended the implementation of alternative teacher education programs that included streamlining teacher certification through alternative routes (Hitz, 2008).

No Child Left Behind Act provisions included the Highly Qualified Teacher (HQT) provision mandates that all students were to be taught by teachers who not only were licensed but who could demonstrate competencies in subject matter that they taught. Hence, every teacher education program requires subject competency assessments. Since only those who pass subject matter tests meet state credential standards and are eligible to teach in public schools, whether or not institutions of higher education meet their goal of one hundred per cent pass rates may suggest the effectiveness of a teacher credential program in meeting NCLB guidelines. Federal policies mandate states and institution of higher education to supply data on how teacher credential candidates meet Federal NCLB mandates of becoming a highly qualified teacher in the subjects that they teach (CTC, 2008).

Many approaches have been suggested as a way to meet NCLB guidelines for becoming a highly qualified teacher. The Council of State School Office (CSSO) recommends beginning teacher performance testing in the areas of common core content knowledge, teaching knowledge, and an assessment of actual teaching similar to the California Teaching Proficiency Assessment (CalTPA) (CSSO, 2008, and CTC, 2010).

As national panels and committees continue to discuss ways of assisting ELs, to reach grade level proficiency, in English, particularly in middle and secondary schools, they focused on studies published by educational reform panels. The Common Core State Standards with rigorous common standards for high school students continues to remain in the forefront of teaching reforms for all students including ELs. The National Governors Association (NGA), the CCSSO, and Achieve, 2008, all support the need for a professional development programs supporting new directions for teaching ELs. (Cochran-Smith and Power, 2010). President Obama and Secretary of Education Duncan support overall reform of our education system including rigorous new standards and assessment for students coupled with developing a more talented and effective teaching force to teach ELs. Both the President and Secretary of Education support teacher education programs based on program data (Obama, 2009).

\section{The Status of English Learners}

In a study of 41 states, 17 percent of English-language learners scored above the state-established norm for reading comprehension (Kindler, 2001). While 10 percent of students who spoke English at home failed to complete high school, the percentage was three times as high (31\%) for language-minority students who spoke English and five times as high (51\%) for students who spoke English with difficulty (National Center for Education Statistics, 2004).

A recent study commissioned by the U.S. Department of Education found that only 11 states met their accountability goals for ELs under the No Child Left Behind Act in the 2007-2008 academic year. The national LEP enrollment increased by 3.52 percent, Title III participation increased by 6.25 percent while immigrant enrollment decreased by 8.8 percent. School districts or district consortia receiving federal-money, reported that 59 percent of ELs achieved their goals including satisfying objectives for progress in English, attainment of fluency in English, and demonstration of proficiency on state tests in reading, math and science. (Pinkos, 2008; Echevarria, 2008; Zehr, 2010a).

The No Child Left Behind (NCLB) Act of 2001 is a United States Act of Congress about the education of children. NCLB was originally proposed by the administration of President George W. Bush and directed through the Senate by Senator Ted Kennedy, one of the bill's co-authors (Library of Congress, 2008). 
Both studies found that many middle and secondary teachers are underprepared to make content comprehensible for ELs (Echevarria, 2008). To close the achievement gap of ELs, classroom teachers need additional training to incorporate both language and content objectives into their lessons to promote academic literacy. However, and most importantly, they need instructional supports that can assist in reducing the achievement gap between ELs and native English-speaking students.

Laura Olsen discusses the plight of ELs in the secondary educational system:

Now, new research sheds light on what happens to English learners over the years they spend in school and identifies a large group of Long Term English Learners (LTELs_-students who enroll in the primary grades and ELs and arrive in secondary schools seven or more years later without the English skills needed for academic success and having accumulated major academic deficits along the way (Olsen, 2010, p 30).

Quality of staffing is a continuing variable as teachers assigned to teach Limited English Proficient (LEP) classes remains a "highly political issue" that is frequently resolved through teacher sonority. Sheltered English courses taught using methods to make content accessible to English language learners, are view by many school districts and teachers as a desirable solution for teaching ELs, but requires the resources of trained teachers and linguistically appropriate materials lacking in most schools. Few schools have trained teacher or appropriate materials for this task. The result is that many ELs do not receive the academic language instruction, or experience classroom teachers skilled in academic content of subject pedagogy (Darling-Hammond, 2010).

\section{English Learners in California}

Survey data from a study by Californians Together found that English-learners in California are largely ignored. Fifty nine percent of English-language learners in middle and secondary schools attending schools for more than six years fail to reach fluent level of English proficiency. Survey data also found that California middle and secondary school students classified, as non-fluent English learners are frequently not placed in an English-language developmental program nor receive school curricula and materials designed for ELs. When they do receive help, it has been inconsistent and fragmented (Zehr, 2010a).

Every California classroom teacher realizes that the complexity of learning a new language and context requires more than English as a Second Language (ESL) support. Attention to academic language is needed in every content area throughout the day. To accomplish this, a new systematic research-based protocol is needed for teaching ELs in middle and secondary schools. The new protocol should be easy to use, accessible and assist teachers in making grade-level academic content more comprehensible while promoting language development (Echevarria, Vogt, and Short, 2008).

During the past two decades, Structured English Immersion (SEI) has been the most popular model for teaching ELs. A variety of factors supports SEI instruction. First, laws passed in Arizona, California and Massachusetts through voter initiatives now requires SEI instruction at the cost of restricting bilingual education. Second, most state student performance assessments are conducted in English with schools or districts that miss targets facing increased scrutiny with possible state sanctions. Third, a large number of ELs reach an intermediate level of English competence after a few years and then stop making progress. This means that they can participate in conversational English but lag in their ability to apply the rules, structures and specialized vocabularies of English necessary for grade level coursework. Consequently, these students continue to score well below English proficient on state tests in English language arts, mathematics and science (Clark, 2009).

Sheltered instruction has long been regarded as a logical set of strategies and activities that middle and secondary teachers can use to assist students to master intermediate or higher proficiency necessary to access gradelevel subject matter (Aha!, 2007).

In California and other states using sheltered instruction, there persists a gap in academic achievement between Caucasian students and those from culturally and linguistically diverse groups. This is compounded by the fact that many teachers are underprepared to make content comprehensible for ELs and few teachers are trained to 
teach initial literacy or content-area literacy to secondary ELs. All newly enrolled California students, in grades K12, whose primary language is not English must take the California English Language Development Test (CELDT) within 30 calendar days after they initially enroll in a California public school. The CELDT must be given once a year to ELs until they are reclassified (CDE, 2011). Most ELs require four to seven years to learn English before they reach average grade level academic English proficiency. The CELDT classifies an ELs English proficiency as beginning, early immediate, intermediate, early advanced and advanced (CDE, 2011).

California is moving in a new direction to meet the challenge of assisting their ELs to become English proficient by focusing on providing teachers with a research-based guide for teaching EL and creating a new teaching credential for teachers looking to provide English language development (ELD) at the secondary level. In 2010, the California Department of Education (CDE) published a research-based state guide for teaching ELs titled, Improving education of English learners: Research-based approaches.

English learners in middle and secondary schools in California now take a separate ELD class in addition to their regular English class. The new EL credential would aim to prepare teachers to teach special ELD classes and provide research-based site and district professional development for teachers of ELs (Zehr, 2010b). The rationale for this new credential is that while regular English/language arts classes typically teach student about literature, ELD classes commonly help students to understand different kinds of language used in various content areas while supporting English literacy development. When implemented, the new credential will be unique in preparing teachers of ELs in the United States (Zehr, 2010b).

\section{A New Protocol for Teaching Middle and Secondary English Learners}

Recently the Sheltered Instruction Operational Protocol was introduced as a new program for teaching and assessing ELs. Several questions surface during a discussion of the use of the SIOP model. First, to what extent does research evidence support the premise the SIOP will contribute to raising ELs English and academic content proficiency? Second, what is the evidence that SIOP can assist teachers in middle and secondary schools to provide students access to grade-level core curriculum in English?

The complexity of moving Els from a beginning English proficiency to an intermediate level of English proficiency requires more than ESL support. Research reported by Echevarria, short \& Powers (2006) documented that when ELs were assigned a prompt requiring expository writing, ELs using the SIOP model of instruction, outperformed and made greater overall gains on the Illinois Measure of Annual Growth in English than ELs in classes with non-SIOP trained sheltered teachers (Echevarria, Short, \& Powers, 2006, Echevarria \& Short, 2010).

Two major SIOP studies using meta-analysis empirical research were conducted with ELs that examined language and literacy development as well as academic achievement. The National Literacy Panel study published an analysis containing several key findings providing guidance for assisting English learners to gain access to the core curriculum. The second study was conducted by a panel from the National Center for Research on Education, Diversity and Excellence (CREDE, 2006). Both panels studied best practices for developing English language skills with a focus on oral language development, literacy development (using instructional and cross-linguistic perspectives) and academic achievement. (Echevarria and Short, 2010; Genesee, Lindholm-Leary, Saunders, and Christian. (2006).

Additional studies conducted from 2005-2010 by the Center for Applied Linguistics, California State University, Long Beach, and the University of Houston have reported positive student results using an experimental design to document increases in student achievement in middle school science classes using the SIOP model (Echeverria and Short, 2010).

During a three-year pilot study of 649 SIOP classes, and 372 control classes in Arlington, Virginia and Long Beach California, seventh grade science lessons were field tested using the SIOP model prior to administrating the new (NCLB) science assessment. Using standardized test measure and mean scores for both pre and post groups, for three of the four measures, students in all SIOP groups significantly outperformed students in comparison groups (Echevarria, 2008). 
Similarly, a study of SIOP was conducted in an Arizona elementary school with a sample population of 450 students that included: ninety-seven percent receiving free/reduced lunches, a highly mobile student population, seventy-four percent limited English proficient (LEP), and 10 percent identified as receiving special education. The study found that 86 percent of third graders taught by teachers using the SIOP, since kindergarten, continued to perform at or above grade level (Echevarria, 2008). This study is significant because as ELs attain English proficiency in kindergarten through grade three, the number of ELs becoming long term ELs in middle and secondary schools can be significantly reduced.

Studies in New Jersey with 225 ELs reported that over a two-year period, students using SIOP outperformed non-SIOP students to a statistically significant level on oral reading, reading, writing and total proficiency (Echeverria and Short, 2010).

A synthesis of these studies documents key finding that have implications for developing academic literacy in middle and secondary schools. Key findings include; 1) the process of second language (L2) literacy development is influenced by a number of variables that interact with each other in complex ways (e.g., L1 literacy, L2 oralcy, socioeconomic status, and more),2) certain primary language L1 skills and abilities transfer to English literacy including phonemic awareness, comprehension and language-learning strategies, and L1 and L2 oral knowledge. 3) teaching the five major components of reading (NICHD 2000) to English learners is necessary by not sufficient for developing academic literacy, 4) academic literacy in a native language facilitates the development of academic literacy in English, 5) English learners who are not at the advanced level of English proficiency need high-quality instruction with instructional adaptations and supports, and 6) ELs require enhanced, explicit vocabulary development to reach English proficiency (CDE, 2010),

\section{Implementation of the SIOP model}

The SIOP model is currently used in all 50 states, and in a number of countries around the world. The SIOP model provides a systematic approach for making content accessible and consistently focuses on academic language development. It incorporates many features recommended for high quality instruction for all student including cooperative learning, reading comprehension strategies, emphasis on the writing process, and differentiated instruction. Specifically, the SIOP contains 30 distinct instructional features grouped into eight components essential for making content comprehensible for ELs including lesson preparation, building background, comprehensible input, lesson strategies, student-teacher interaction, student practice and application, lesson delivery and review and assessment ((Echevarria, 2008; Echeverria \& Short, 2010). The SIOP protocol is useful for teachers as an observational rating instrument, a lesson and planning delivery system, a research tool for measuring level of implementation and fidelity, lesson plan and delivery, and as a model for comprehensive district professional development institutes and workshops (Echevarria, 2008).

\section{Assessing English Language Learners Using the SIOP}

Teachers of ELs need to consider several factors when developing assessments and making decisions regarding testing accommodations for ELs. These factors are not considered guidelines but rather provide useful context for assessing ELs including language factors, educational background, varying degrees of formal schooling in English, varying degrees of exposure to standardized testing, and varying degrees of acculturation to the U. S. school system. The planning process for assessment development in classrooms with ELs should include several criterion to insure validity. Assessment validity include: 1) clarity of the test purpose so that valid interpretations may be made on the basis of test scores, 2) a precise and clear definition of the construct the test is intended to measure, 3) defining the test content and explaining how content will be assessed, 4) reviewing state content standards and other documents that provide performance standards and other expectations for student achievement, 5) designing assessments that will allow multiple opportunities and ways for ELs to demonstrate what they know, 6) develop a careful rationale for weighting individual test items so as not to provide a disadvantage to ELs by assigning greater weight to long answers written in English, 7) acknowledging that designing assessment and response forms with large amounts of text make is less likely that ELs will experience assessment success, and 8) the assessment agency designing the assessment should supply information about the cultural backgrounds of its test taking populations, including ELs. (Pitoniak, M.J., John W. Young, Martiniello, M, King, Buteux, A, and Ginsburgh (2009). 
Using the eight components of the SIOP framework, Echevarria and Short (2010) developed a five step Likert-type scale of measuring student progress for each of the eight SIOP components (Echevarria \& Short, 2010). The key assessment features include assessment of reading and writing ability, graphic support and bolded key words, and text elaboration and simplification that meet assessment design recommendations for ELs. All items vary in range in levels of difficulty and include short and extended frequent written student responses. Use of the SIOP supports building knowledge of content language necessary to answer test questions. .

\section{CONCLUSION}

The underachievement of ELs on both state and national level assessments underscores the need for teachers to rely on more than theoretical models of best practice or to implement a few strategies for second language learners. Teachers need a flexible model of systematic instruction to assist ELs to develop academic literacy skills needed for success in mainstream classes, for meeting content standards and for passing standardized assessments in their second language.

Middle and secondary students are the forgotten population of non-proficient English students making up more than 30 percent of school populations Few people would disagree that English language proficiency is necessary for academic success in U.S. schools. Structured English immersion taught in states with high populations of ELs can form the basis for assisting students to reach an intermediate levels of English proficiency but whose writing is compromised with errors.

This paper supports the implementation of the SIOP for instruction and assessment of ELs in both developing English language proficiency and teaching content materials in context. This paper argues that the SIOP meets national panel recommendations for what teachers should know and be able to do, to successfully teach and assess ELs. Preliminary research supports the use of the SIOP to increase ELs English proficiency and content comprehension. A major strength of the SIOP model is that it allows teachers to organize instructional practices and incorporate their favorite lesson strategies from their own experiences, while being reminded of important features that may be overlooked in the ebb and flow of middle and secondary classroom instruction (Echevarria \& Short, 2010). The SIOP is an efficient and practical way to replace current political ways of teaching ELs and moving teaching of ELs into the arena of research based teaching strategies and protocols.

Further research in teaching ELs using the SIOP model is needed in middle and secondary schools, but preliminary results support the value of the SIOP in moving ELs toward reclassification of English proficiency from an intermediate level of proficiency, (limited communication, memorized phrases statements and questions) to an early advanced level of English proficiency that will enable ELs to comprehend academic content in context. The SIOP can be used to help ELs reduce errors that complicate communication and prohibit ELs from reaching an early advanced level of English usage necessary to participate in oral and written communications characterized by discourse that is more elaborate. English learners advancing to the early advanced level of English proficiency, make fewer errors, and rarely complicate written communication-allowing students to participate in most academic domains (CDE, 2011).

Finally, this paper recognizes the benefits of using the SIOP as a practical solution to teaching grade level standards based, core content lessons to students learning English, academic content and the language of standardized assessment. The SIOP can also be used as a flexible model for developing school site workshops and district institutes.

\section{AUTHOR INFORMATION}

Dr. Luster is an acknowledged community educational leader holding several graduate degrees including a doctorate from the University of Southern California. He is an experienced teacher, and a school, district and county office administrator. Dr. Luster received a commendation for his contributions to the California Department of Education from the California Superintendent of Public Instruction. He is currently an assistant professor at National University where he twice received a Distinguished Professor Award. Dr. Luster currently serves as University TPA coordinator and lead teacher education Faculty for the Sacramento Center. He has published several articles on reforming teacher education and teaching English learners. E-mail: jluster@nu.edu 


\section{REFERENCES}

1. Aha! (2007). Report of state-wide district survey to the Arizona English language learner task force. Tempe, Az: Author.

2. August, D., \& Shanahan, T. (2006). Developing literacy in second-language learners: Report of the National Literacy Panel on language-minority children and youth. Center for Applied Linguists. Lawrence Erlbaum Associates.

3. CTC-California Commission on Teacher Credentialing. (2008). Teaching performance assessment. At: http:/ctc.ca.gov/educator-prep/CalTPA.html on June 15, 2008.

4. CTC-California Commission on Teacher Credentialing. (2010). The implication of the adoption of common core standards on teacher education: At: http://www.ctc.ca.gov/commission

5. CTC-California Department of Education (CDE). (2010). Improving education for English learners: research-based approaches. Sacramento, CDE press.

6. CTC-California Department of Education. (2011). California English Language Development (CELDT) Testing. At: http://www.cde.ca.gov/ta/tg/el/documents/blueprnt2010.doc

7. Clark, (2009). The case for structured English immersion. Educational Leadership. April 2009. 66(7).

8. Council of Chief State School Officers (CCSSO), \& Achieve. (2008) The future of teacher licensure testing. At http:/www.ccsso.org

9. Cochran-Smith, M., \& Power, C. (2010). New directions for teacher preparation. Educational Leadership 67:8 (6)

10. Darling-Hammond, L. \& Bell, D. L. (1997). Teaching for high standards: What policy makers need to know and be able to do? National Commission on Teaching \& America's Future. At:

http://govinfo.library.unt.edu.

11. Darling-Hammond, L. (1997). Doing What Matters Most: Investing in Quality Teaching. National Commission on Teaching and America's Future, New York.

12. Darling-Hammond, L. (2008). A future worthy of teaching for America. Phi Delta Kappan, 89:110.

13. Darling-Hammond. (2010). The flat world and education: How America's commitment to equity will determine our future. Teachers College, New York and London

14. Echevarria, J. (2008). Making standards-based lessons understandable for English learners: The SIOP model. Center for Research on the Educational and Achievement and Teaching of English Language Learners. Berkley.

15. Echevarria, J., Short, D., \& Powers, K. (2006). School reform and standards-based education: An instructional model for English language learners. Journal of Educational Research, 99(4) 195-210.

16. Echevarria, J.,Vogt, M.E. \& Short, D. (2008), Making content comprehensible to English learners: The SIOP model. Boston: Pearson/Allyn and Bacon

17. Echevarria, J., \& Short, D. (2010). Programs and Practices for Effective Sheltered Content Instruction. In California Department of Education, Improving Education For English Learners: Research Based Approaches. 251-303.Sacramento: CDE Press

18. Echevarria, J., \& Short, D. (2011). Programs and practices for effective sheltered content instruction (Webinar 4). At: http://www.schoolsmoving up.net/pdf/SchoolsMoving up ELL Series 2010-11)

19. Ferguson, R. (1991summer). Paying for public education: New evidence on how and why money matters. Harvard Journal of Legislation, 28,(2). 465-498.

20. Genesee, F., Kubdgikn-Leary, K., Saunders, W., and Donna Christian. (2006). Teaching English language learners: A synthesis of research evidence. New York: Cambridge University Press.

21. Hitz, R. (2008). Can the teaching profession be trusted? Phi Delta Kappan, 89:110.

22. Honavar, V. (2008). Teachers achieving 'highly qualified' status on the rise. Education Week. At: http://edweek.org, on June 11, 2008.

23. Kindler, A.L. (2002). Survey of the states' limited English proficient students and available educational programs and services: 2000-2001 summary report. Washington, DC: National Clearinghouse for English language Acquisition

24. National Center for Education Statistics. (2004). The condition of education, 2004. At: http://nces.ed.gov/programs/coe 
25. National Governors Association, Council of Chief State School Officers and Achieve. (2008).

Benchmarking for success. Ensuring U.S. students receive a world-class education. Washington, DC:

National Governors Association)

26. National Institute of Child Health and Human Development (NICHD). (2000). Report of the National Reading Panel/ Teaching Children to read: An evidence-based assessment of the scientific research literature on reading and its implications for reading instruction (NIH) Publication NO. 00-4769). Washington, DC: U.S. Department of Health and Human Services.

27. Obama. B. (2009). Remarks by the President to the Hispanic Chamber of Commerce. Available: www.whitehouse.gov/the pressoffice/Remarks-of-the President-to-the-United States Hispanic Chamber of Commerce

28. Olsen, Laurie. (2010). Changing course for long term English learners. Leadership. November/December 2010, (30). Association of California School Administrators.

29. Pinkos, M. P.(2008). Addressing achievement gaps: The language acquisition and educational achievement of English language learners. Office of English Language Acquisition. U.S. Department of Education, Princeton, N.J.

30. Pitoniak, M.J., John W. Young, Martiniello, M, King, Buteux, A, and Ginsburgh. (2009). The guidelines for the assessment of English language learners. Listening, Learning Leading. Educational Testing Service. At: www.ets.org.

31. White, M. E., Makkonen, R., \& Stewart, K. B. (2009). Multistate review of professional Teaching standards (Issues \& Answers Report, REL 2009-No.75: Washington, D.C:U.S. Department of Education, Institute of Education Sciences, National Center for Education Evaluation and Regional Assistance, Regional Educational Laboratory West. At: http://ies.ed.gov/edlabs.

32. Zehr, M. A. (2010a). Study finds ELL students languishing in California schools. Education Week. At: www.edweek.org.

33. Zehr, M.A. At (2010b). California to create teaching credential for secondary ELLs. Education Week. At: www.edweek.org.

34. Zehr, M.A. (2011). Few states meeting goals of NCLB for English-learners. Education Week. At: www.Edweek.org. 


\section{NOTES}

